\title{
Government under pressure: investing in better outcomes through social impact bonds
}

\author{
Sandra Hodzic*
}

\begin{abstract}
With shrinking resources and declining federal transfers, provincial governments across Canada are forced to provide increased levels of supports to vulnerable individuals with decreasing resources (Janssen \& Estevez, 2013). Governments continue to face obstacles in meeting the needs of vulnerable populations such as children, single parents, and those who are homeless, to name a few. Manitoba, for instance, faces demographic challenges related to an influx of newcomers who are seeking refuge, resettlement, and housing supports, an aging baby boomer population that will need end-oflife supports, as well as a growing number of children in government care. Instead of funding programs based on their activities and outcomes, this paper presents outcomes-based financing, such as the social impact bond, that reward service providers who are able to demonstrate proof of outcomes and can show how the intervention improved the lives of the individuals it was meant to serve. Under a social impact bond, government engages non-traditional partners in the private and non-for-profit sectors, and the community as a whole becomes part of the solution to challenging social problems.
\end{abstract}

Key Words Outcomes-based financing; social impact bond; community; vulnerable individuals; outputs; activities; child welfare.

Journal of CSWB. 2018 Oct;3(2):43-46

www.journalcswb.ca

\section{INTRODUCTION}

In an arena where multiple players are competing for scarce resources, it becomes increasingly important to demonstrate that social program supports lead to an effective outcome to ensure their continuation. Traditional methods of funding social services, such as activities and outputs-based programs, have not always demanded evidence of how the program improved the life of the recipient(s) receiving the intervention. This lack of focus on outcomes has discouraged some service providers from pursuing long-term goals that have become a recent trend and a condition of securing future funding (Bugg-Levine, 2017; Klem, 2017).

Many governments and service providers have failed to distinguish outputs versus outcome when assessing program effect. The former has been the central driver of funding decisions, but the problem is that it focuses on results that are achieved shortly after program implementation (e.g., creation of ten extra hospital beds) without demonstrating effect. Continuing with the health care analogy, outcomes focus on the underlying issue(s) which lead to hospitalization in the first place, and they strive to transition the patient and keep her out of the hospital in the future. Another reason government has tended to fund programs based on activities and outputs is due to a lack of data and Information Technology infrastructure needed to evaluate and track client outcomes, which has made it more difficult to establish cause and effect.

This growing trend with demonstrating outcomes has led some jurisdictions to redefine the way they offer social services by introducing pay-for-performance tools that prompt program payment once there is evidence that an intervention has been successful at reaching a specific outcome. The most frequent example of a pay-for-performance model is the social impact bond (SIB), which represents a major renewal to the way government has delivered social services in the past. Under SIBs, a service provider borrows money to operate the program and the service provider repays that money back to the lender only if the program is able to successfully meet its targets (MaRS, 2017).

Pay-for-performance structures like SIBs offer service providers more latitude and flexibility to design and deliver interventions without government interference, which was uncommon under traditional service delivery contracts (Bugg-Levine, 2017). They also provide an additional option of funding difficult social problems based on measurable evidence of success. SIBs rely on community experts, Indigenous partners, and other sector professionals to become part of the solution, while government facilitates and empowers them to help define a positive solution. SIBs have gained global popularity in the last decade and most can now be 
found in the United States, United Kingdom, and other parts of Europe, Australia and, more recently, in Canada (Social Finance UK). They are most often delivered in areas that require a creative solution to a complex social problem such as rehabilitation and youth employment, homelessness, juvenile delinquency, child welfare, and recidivism. The proliferation of SIBs, and impact investing more generally, is most popular with Generation $X$ and $Y$ investors because they tend to share a common vision of social responsibility (Fidelity Charitable, 2018).

SIBs generally begin when government issues a contract with clear deliverables and measurable outcomes that may be used as a basis for assessing program success. SIBs consist of a group of partners including, but not limited to, government, private/business investors, an intermediary, third-party service provider, an evaluator, and the target population, and each partner has a unique and specific function. The role of the service provider is to deliver a specific social service, such as reducing the number of children in state care, by following specific metrics and measures of success that are established at the beginning of the program. Many SIBs also have an intermediary; a third party who serves as a liaison between government and service provider to assist with various program components. The intermediary commonly supports investor engagement and identifies investors who are interested in contributing to a specific cause.

MacDonald (2013) has used the Dragon Den's analogy to explain the multi-stakeholder relationship under SIBs more clearly. MacDonald says that social programs are "pitched" to a private investor and its attractiveness is based on the rate of return and opportunity for future capital. However, this is not the only driver of investor engagement. Many investors who contribute to a SIB are often socially driven individuals and philanthropists who are inspired to invest in a given social cause due to a sense of personal responsibility. In some cases, investors also have an opportunity to collect a return on their investment, depending on the service provider's ability to meet specific program targets. However, in other cases, their investor contributions are purely philanthropic and all proceeds are re-invested back into the project, as has been the case with the Mah family in Saskatchewan's Sweet Dreams SIB (Loxley, 2017).

Program outcomes are validated by an independent evaluator who determines the degree of success and the scope of investor return. Returns on investment typically range from five to ten per cent, depending on program scope and geography. If the evaluation proves successful, government pays investors their principal amount, plus a return. Under this scenario, investors may lose some or all of their money, depending on the degree of success. This has been one of the more attractive elements of SIBs because investors are essentially de-risking the service provider and government from investing in unsuccessful initiatives that do not produce positive outcomes.

SIBs give investors a chance to define, or be a part of, solving a social problem and contributing to outcomes by investing in, rather than funding, social programs through taxes. MacDonald (2013) explains that governments can, and often do, save money from SIB investments because the improved social outcomes offset future expenditures that government would have incurred in the absence of a SIB.
Recent research suggests that paying for outcomes is superior to paying for activities because it creates a demand that begins to reshape institutions, behaviours, relationships, and culture (Erickson, 2017). SIBs are one tool that governments can leverage to meet critical demand and help improve social outcomes to deliver meaningful results based on shared priorities. These priorities may include any number of things such as reducing the rates of recidivism, improving health care outcomes among pre-hypertensive individuals, or, as in Manitoba's case, reducing the number of children in government care.

\section{Using SIBs to Fund Child Welfare in Manitoba}

Manitoba has faced, and continues to face, a high number of children in government care compared to other Canadian jurisdictions. As a potential response to this ongoing trend, Manitoba had formally engaged community partners in the private and non-for-profit sectors to assist with resolving this pressing challenge by selecting its first SIB in child welfare. The goal of this program is to assist at-risk mothers with keeping their children at home (including faster reunification) and to prevent them from entering into care. Manitoba hopes to issue a public SIB announcement, jointly with its service provider, in the fall of 2018.

\section{Other SIBs in Child Welfare}

Social Finance UK's global database for impact bond's shows that there are more than a dozen social impact bonds globally in the area of child welfare. While the performance for the majority of these programs remains inconclusive, evidence shows that at least three child welfare SIBs, to date, have demonstrated effective outcomes (Social Finance UK website). The Uniting Care Burnside SIB and the Benevolent Society are both Australia-based SIBs. The goal is to reunite children in out-of-home care with their families and prevent children from entering into out-of-home care. Evidence from the Uniting Care Burnside SIB has shown that 63 per cent of children in government care were safely reunified with their families at the end of year five and most of those children would otherwise have been in government care in the absence of this intervention (Social Ventures Australia, 2018). The third child welfare SIB, Partnering for Family Success, is based in Ohio, United States, and its goal is to reduce the number of days that children spend in care by supporting their families, many of whom struggle with homelessness and addictions that often leads to family breakdown and child apprehension. A final report regarding the outcomes of this program is currently underway, but a preliminary evaluation shows generally positive results. Clients who received the treatment were significantly less likely to access emergency shelters, and there were no cases of child maltreatment in the control group compared to 6 per cent in the treatment group (Bai, Collins, Crampton et al., 2017).

In all of these examples, treatment families have shown less involvement with the child welfare system and more focus on the families' overall well-being. This wellbeing spans beyond immediate gains and highlights the importance of long term benefits associated with family restoration. The rhetoric is redefined to include outcomes and tangible life improvements stemming from family reunification, as opposed to immediate gains that fail to target the 
underlying issue, which often leads to the intervention in the first place.

\section{CONCLUSIONS}

In order to be effective, the SIB will need explicit support from leadership across all three sectors: public, private and non-for-profit. This, in turn, will create critical momentum around the social services economy through a renewed focus on outcomes. Investing and paying for outcomes (e.g., number of children that were safely reunified with their families and who stayed with their families for a year post-program) as opposed to outputs (e.g., number of children apprehended from their homes) reorients the funder/grantee relationship around long-term results instead of short-term rewards. This leads to a positive and lasting change in the life of the program recipient, and it strengthens the accountability between the funder and the funded.

In order to meet our current and future demand, governments need to redefine their relationship with service providers. This means ensuring that service providers are able to demonstrate positive outcomes that governments will use as the basis for making challenging policy decisions. This is especially important at a time when governments are challenged to provide increased supports with declining resources and reduced federal transfers, as well as shifting demographic and geopolitical uncertainties (Eisen, Murrell, \& Fantauzzo, 2014). These pressures are forcing many to rethink the way funding decisions have been made. This means placing more accountability on service delivery organizations to provide proof of outcomes as a condition of receiving continued funding supports. SIBs are one tool that offers this advantage.

The successful implementation of this outcomes-based model requires an ideological shift in the way government operates within the public sphere. In addition to a change in policy, SIBs may inspire a host of questions related to ethical, financial, economic, environmental, and social considerations that may lead to a shift in the way social services have been delivered in order to meet current and future demand. One question remains: Are we willing to welcome the change?

CONFLICT OF INTEREST DISCLOSURES

The author declares that there are no conflicts of interest.
AUTHOR AFFILIATIONS

*Department of Families, Government of Manitoba, Winnipeg, MB.

\section{REFERENCES}

Bai, R., Collins, C. C., Crampton, D., Lui, C., \& Fischer, R. (2017). Briefly Stated Research Summary. Cuyahoga Partnering for Family Success Process Evaluation. Cleveland, $\mathrm{OH}$ : Center on Urban Poverty and Community Development, Case Western Reserve University. Retrieved June 21, 2018 , from http://povertycenter.case.edu/wp-content/uploads/2017/07/ Briefly_Stated_No_17-01_Cuyahoga_Partnering_for_Family_Success. pdf

Bugg-Levine, A. (2017). From funding activities to investing in results: How do we get from here to there? In What matters: Investing in results to build strong, vibrant communities (pp. 472-479). San Francisco, CA: Federal Reserve Bank of San Francisco.

Eisen, B., Murrell, D., \& Fantauzzo, S. (2014). Declining equalization payments and fiscal challenges in the small "have-not" provinces (Electronic version). Halifax, NS: Atlantic Institute for Market Studies.

Erickson, D. J. (2017). The march toward outcomes-based funding. In What matters: Investing in results to build strong, vibrant communities (pp. 29-54). San Francisco, CA: Federal Reserve Bank of San Francisco.

Fidelity Charitable. (2018). Impact investing: At a tipping point? Boston, MA: Fidelity Charitable. Retrieved June 21, from https://www.fidelitycharitable. org/docs/impact-investing-survey.pdf

Janssen, M. \& Estevez, E. (2013). Lean government and platform-based governance-Doing more with less (Electronic version). Government Information Quarterly, 30, S1-S8.

Klem, K. (2017). More services, less wasteful spending: pay-for-success as an innovative strategy to combat the opioid crisis. In What matters: Investing in results to build strong, vibrant communities (pp. 277-288) San Francisco, CA: Federal Reserve Bank of San Francisco.

Loxley, J. (2017). Social impact bonds and the financing of child welfare (Electronic version). Winnipeg, MB: Canadian Centre for Policy Alternatives Manitoba

MaRS Centre for Impact Investing. (2017). The pay-for-success opportunity: From activities to outcomes. Toronto, ON: MaRS.

MacDonald, D. (2013, December). Social impact bonds: They aren't charity. They aren't social justice. They're a new way for business to profit from social services (Electronic version). Calgary, AB: Alberta Views.

Social Finance UK. London, UK. Home page available from www.socialfinance.org.uk

Social Ventures Australia. (2018). Newpin Social Benefit Bond Annual Investor Report June 2018. Brisbane, Australia: Social Ventures Australia. Retrieved August 1, 2018 from https://www.socialventures.com.au/assets/ Newpin-SBB-Annual-Report_30-June-2018.pdt 


\section{APPENDICES}

Appendix A: Global Overview of Social Impact Bonds

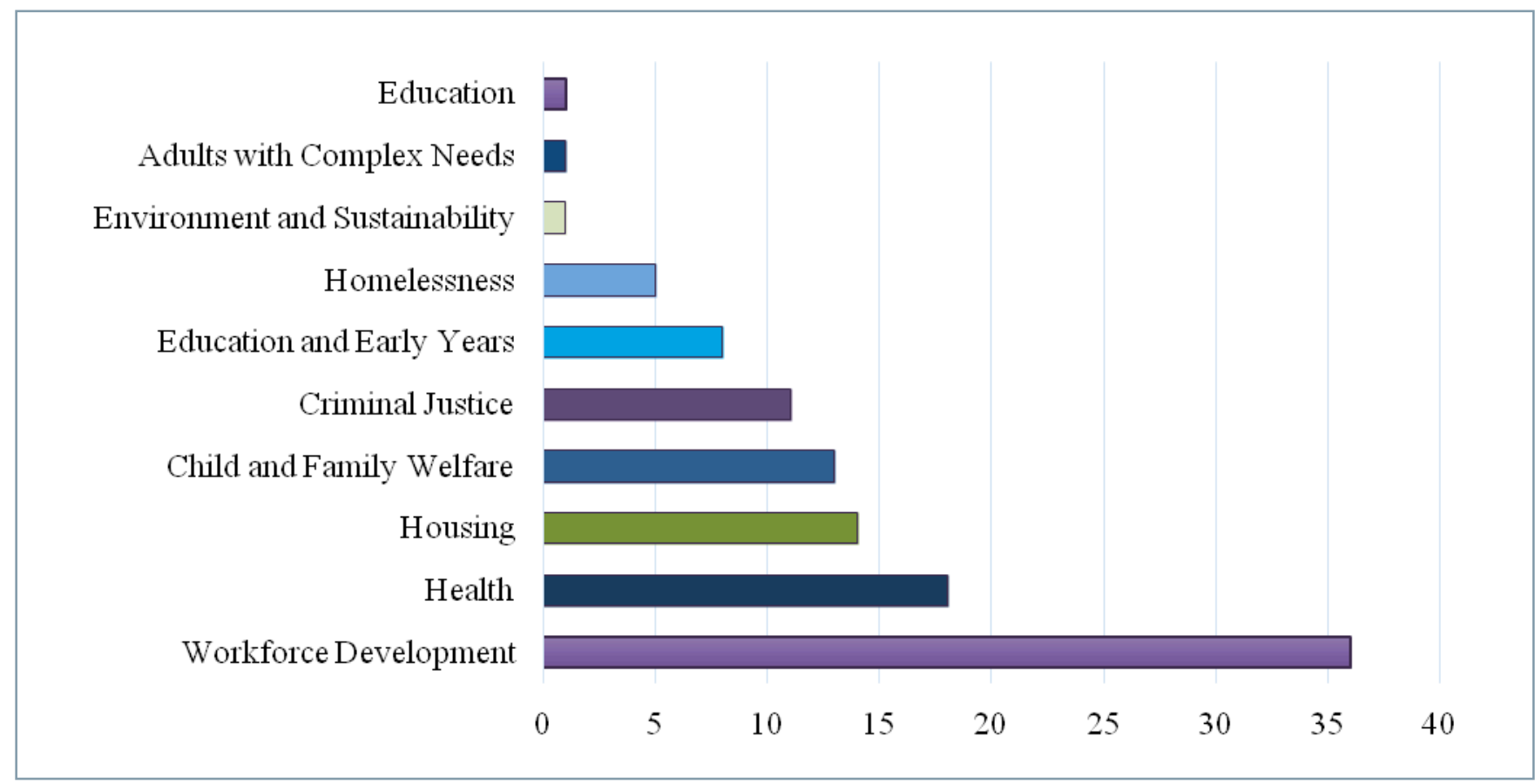

Source: Social Finance United Kingdom, 2018. 